\title{
OS EXCESSOS DA IDENTIDADE: BENTO XVI E A QUESTÃO DA TOLERÂNCIA*
}

\author{
Homero Santiago
}

De tempos para cá, talvez mesmo décadas, as religiões voltaram a ganhar importância. Por um lado, recobraram seu peso na vida pessoal, seja como código moral que estipula condutas, seja como fator de identidade de grupos; por outro lado, e em decorrência, um acirramento das tensões e disputas religiosas restituiu à fé a condição de dado a ser considerado inclusive na geopolítica mundial.

Com efeito, vivemos num mundo religiosamente agitado, não poucas vezes religiosamente abalado. E ainda que possamos suspeitar que nem sempre os conflitos que surgem sob carapaça religiosa de fato tenham matriz religiosa, não é pouco significativo que justamente se representem e se apresentem como tais, quer dizer, a religião faz-se uma forma privilegiada de enquadrar os conflitos e inclusive res-

\footnotetext{
* Este trabalho começou a nascer em maio de 2007, quando o discurso de Bento XVI na V Celam suscitou-nos o desejo de compreender a base teórica das afirmações ali contidas, especialmente aquelas concernentes à evangelização dos índios americanos. Versões iniciais foram apresentadas e discutidas na I Semana de História da filosofia moderna da Unifesp-Guarulhos, novembro de 2007, e nas jornadas "Exceso y prudencia" da Universidad Nacional de Córdoba, Argentina, maio de 2008. Uma versão resumida do texto apareceu na revista Discutindo Filosofia, no 13 , julho de 2008.
} 
ponder a alguns dos problemas de nossa época ${ }^{1}$. Desse ponto de vista, a reflexão sobre o fato religioso em seu sentido mais amplo e, sobretudo, em suas conseqüências - problema que há não muito tempo quiçá parecesse superado e de alcance restrito - pode reencontrar um inusitado interesse.

Tendo como fundo esse contexto é que gostaríamos de propor uma breve reflexão acerca das relações entre o polêmico pontificado de Bento XVI e a questão da tolerância - tópico que merece hoje renovada atenção. Ao criar dificuldades para o ecumenismo entre os cristãos, imiscuir-se com tenacidade em assuntos laicos e condenar a autonomia da razão, despertar a ira do mundo islâmico, tentar erigir uma nova ortodoxia, enfim, o sumo pontífice põe em xeque uma das mais importantes construções da cultura ocidental: o ideal de tolerância religiosa, cuja decorrência prática é a possibilidade da convivência pacífica entre os credos a partir do respeito mútuo. Nosso percurso será, sumariamente, o 196 cruzamento do que cremos ser a lógica básica da tolerância, de um lado; de outro, a lógica do cristianismo defendido por Bento XVI. Pois se a primeira revela-nos a prudência de uma razão que teve de aprender às turras a lidar com alguns

\footnotetext{
${ }^{1}$ Assim, para ficar num exemplo de colorido local, dificilmente alguém poderá atribuir o fenômeno da violência urbana brasileira a um pretenso império da irreligiosidade; no entanto, um dos grandes argumentos em favor do projeto "Deus na escola" - que previa o ensino religioso nas escolas estaduais paulistas e chegou a ser aprovado pela Assembléia Legislativa, sendo depois vetado pelo executivo - foi o combate à violência. "Numa sociedade cujos valores se invertem e na qual o respeito é assunto desconhecido, o que fazer? Atitudes positivas para restabelecer a ordem e apaziguar os ânimos são bem-vindas. [...] Se vivemos a violência e a desestrutura de lares causadas por más influências e descaminhos, por que rejeitar a oportunidade 'facultativa' de acesso a Deus?" (Amary, 2007) O peculiar nessa argumentação da deputada Maria Lúcia Amary em favor do projeto de lei de sua autoria, queremos crer, não é a idéia de que se deve ensinar religião às crianças, mas a articulação entre um problema social amplo e a religião como uma doutrina que pode explicar e transformar o mundo. E mesmo que isso não seja inteiramente novo, não deixa de surpreender que ainda possa ser aventado com alguma seriedade; quer dizer, o que surpreende é a repetição de um fundo religioso como elemento sem o qual a realidade se desorganiza e corrompe-se. Para tudo isso, ver Chaui (2004).
} 
de seus rasgos mais inquietantes; a segunda, parece-nos, é a forma acabada de um excesso que resvala para a destruição do diferente - excesso de identidade que talvez seja a conseqüência extrema do próprio monoteísmo em questão.

Antes de tudo, porém, que o leitor nos permita a breve retomada de alguns marcos desse pontificado; um sumário sem pretensão de exaustividade, em geral baseado no que publicou a grande imprensa, cujo único fim é reavivar a memória de certos fatos e documentos que estarão aqui em discussão.

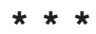

Em abril de 2005, o cardeal alemão Joseph Ratzinger é eleito papa e toma o nome de Bento XVI. No natal deste ano ele apresenta a carta encíclica Deus caritas est (Deus é amor), documento que sintetiza sua interpretação do cristianismo e do papel da Igreja e está destinado a balizar teoricamente o seu pontificado.

Em setembro de 2006, em viagem à Alemanha, o papa tece duras críticas à idéia de autonomia da razão, tachando de "irracional" toda tentativa teórica que faça economia da fé e do lógos criador divino que daria a base oculta de qualquer saber. Assim, se "desde o Iluminismo" a ciência fez diminuir o papel de Deus, caberia lembrar que, adverte, "as contas sobre o homem, sem Deus, não quadram, e as contas sobre o mundo, sobre todo o universo, sem Ele não quadram" (Bento XVI, 2006b). É ao longo dessa mesma viagem que trechos de um discurso enfurecem muçulmanos de todo o mundo ao, mediante uma citação, qualificar Maomé de portador de “coisas más e desumanas" e acusá-lo de querer "propagar, através da espada, a fé que pregava” (Bento XVI, 2006a).

Em maio de 2007, no Brasil, na abertura da V Celam (Conferência geral do episcopado da América Latina e do Caribe), referindo-se à colonização do continente americano, o papa afirma que a cristianização da América "não 
supôs, em qualquer momento, uma alienação das culturas pré-colombianas, nem foi uma imposição de uma cultura alheia” (Bento XVI, 2007).

Em julho de 2007, um documento oficial do Vaticano define a Igreja católica como a "única igreja" de Cristo. As igrejas protestantes não seriam "igrejas” em sentido próprio, e a graça divina que algum de seus seguidores poderia eventualmente atingir seria sempre menor que a de um católico.

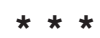

Dado isso, passemos a algumas considerações acerca da idéia de tolerância, a fim de não restarmos no vazio da indefinição do termo e podermos simultaneamente apreender algo de sua lógica. Restringimo-nos à questão da tolerância religiosa, mas a nosso ver o mesmo raciocínio vale para a tolerância em geral.

A idéia de tolerância é uma idéia complexa, pois englo198 ba duas noções que, embora à primeira vista contraditórias, combinadas garantem a sua consistência. Tais noções são igualdade e diferença. Aquele que não partilha de minhas crenças é diferente de mim, pode ser que eu tenha uma religião e ele tenha outra ou nenhuma. Por outro lado, ele é igual a mim, na medida em que há igualdade de todos ao direito de livre crença, especialmente diante da lei, que deve assumir uma posição de neutralidade em matéria religiosa (não, frisemos, de ateísmo, pois seria já tomar um partido).

Por isso é que, só em aparência, igualdade e diferença, em tal assunto, se contradizem. No fundo, uma não existiria plenamente sem a outra; entre elas há um equilíbrio mútuo: é porque todos são em algo iguais que todos podem ser diferentes, e para que cada um possa gozar de sua diferença é que todos devem ser iguais. O resultado dessa implicação recíproca é o estabelecimento de um terceiro elemento, o efeito de ouro da tolerância: o respeito a todas as crenças, a todas as manifestações religiosas - com uma única ressalva: 
desde que não firam os direitos de outras religiões e aqueles reconhecidos a todas as pessoas, indistintamente. Para tomar um exemplo limite, imaginemos um caso de sacrifício humano com fins religiosos. Ele é condenável, decerto, mas não por revelar idolatria, barbarismo, ou coisa do tipo; não cabe um juízo acerca do valor, da verdade ou da falsidade da fé que exige o sacrifício, apenas a condenação do próprio sacrifício como atentado a um direito comum, garantido por lei, que é a vida. Nessa medida, o sacrifício é condenável como o é qualquer assassinato, não porque manifestaria um erro religioso; e ainda que o traço religioso do assassinato sacrificial possa constituir um fator do ajuizamento legal (crueldade, motivação fútil etc.), o pode como outros elementos o podem, não por sua peculiaridade religiosa.

No decorrer da história da idéia de tolerância, não foi fácil chegar a essa clareza acerca do que cabe ou não ao Estado ajuizar em matéria religiosa. Seja como for, certo é que nesse percurso foi fundamental reconhecer certa relatividade de toda e qualquer verdade religiosa: cada religião pode pretender estar com a verdade, por isso mesmo, aos olhos do poder público, nenhuma pode ter a verdade absoluta; ou seja, é justamente porque todas as religiões podem alegar a sua verdade que nenhuma é mais verdadeira que outra. Nesse campo, todos têm direito à sua verdade, mas as verdades são múltiplas, equivalentes, e ninguém pode querer impingir a sua aos outros.

Assim esboçada, a idéia de tolerância religiosa surge indissociável de certo processo de relativização que culmina na noção de um absoluto relativo (o que não significa, necessariamente, uma relatividade absoluta). Trata-se de uma conquista lograda no decurso um longo processo de maturação, inacabado (talvez sem término), em que o pensamento teve de aprender a respeitar a prática, a lidar com a realidade dos homens e de seus diversos desejos, anseios e concepções - às vezes cordatos e bem-intencionados, às vezes sanguinários e violentos. Em poucas palavras, diríamos que a tolerância religiosa é um 
construto que resulta de um processo de autoconhecimento da razão, que prudentemente impõe limites a seus próprios impulsos dominadores, absolutizantes - em especial os que se manifestam nas religiões e que, na ausência de um meio tolerante, condenam-se à disputa e, por vezes, à guerra².

\section{$\star * *$}

Desde que se preste atenção a essa lógica da idéia de tolerância, seus constituintes (igualdade e diferença) e seu efeito maior (respeito mútuo), não é difícil perceber por que os atos de Bento XVI provocam tamanha polêmica.

O seu catolicismo não se contenta com a sua verdade, mas gostaria que essa verdade, que é sua, fosse também a de todos os outros reunidos numa identidade superior - que pode ser dita, em princípio, a do cristianismo, mas que ao fim e ao cabo reduz-se àquela da própria Igreja Católica, que nunca escondeu suas pretensões universalizantes (não custa lembrar 200 que o sentido original de "católico" é universal), crendo-se a "única igreja” de Cristo. Verdade única, de um Deus único, criador de uma única humanidade e que instituiu como sua uma única Igreja. O império da unicidade é o que justificaria a projeção avassaladora de uma identidade superior sobre todos os homens e povos e o anelo maior de supressão de todas as diferenças, quer de direito, quer de fato.

É claro, porém, que esse objetivo não pode ser simplesmente apregoado: "destruamos o diferente". Não cairia nada bem no limiar do século XXI e num mundo marcado por rivalidades religiosas, podendo abrir uma série de feridas his-

\footnotetext{
${ }^{2}$ Insistimos nisso porque podemos concordar com Alain de Libera, quando identifica na idéia iluminista de tolerância certo abrandamento das idéias de verdade e de absoluto religiosos e da intenção de instaurar uma unidade teológica; porém, não precisamos acatar a avaliação de que isso constitua "um tipo sofisticado de "preguiça intelectual'" próprio da modernidade. A fórmula é do entrevistador, Luiz Felipe Pondé, mas de Libera aparentemente acede a ela (cf. Pondé, 2002). Pelo contrário, longe de qualquer preguiça, a idéia de tolerância é testemunha de um enorme trabalho da razão.
} 
tóricas mal cicatrizadas. É por isso que a nova cruzada terá como palco privilegiado o das idéias e dos dogmas - arena em que Bento XVI, teólogo de sólida formação e durante longos anos prefeito da Congregação para a doutrina da fé (a antiga Inquisição), conhece todas as armas. Tratar-se-á de estabelecer uma nova ortodoxia, a qual se fundará curiosamente na idéia de amor. Se pudermos dar numa só frase um apanhado do conteúdo mais profundo da religião de Bento XVI, será esta: "em última instância, somente a verdade unifica, e a sua prova é o amor" (Bento XVI, 2005) ${ }^{3}$.

Todo o nosso problema, então, gira em torno do que vem a ser tal "amor". Para buscar aclará-lo, é necessário repassar brevemente o núcleo mais duro e programático do ideário papal, ou seja, a encíclica Deus é amor. Que amor é esse?

Em grego, explica a Encíclica, havia três palavras para "amor": eros-amor entre homem e mulher; philia - amor de amizade; e agape - termo "quase posto de lado" na linguagem corrente e de que os cristãos se apropriarão para um uso específico ${ }^{4}$. $\mathrm{O}$ que se tem no Novo Testamento é o uso de philia, "com um significado mais profundo", para exprimir a relação de Jesus com os discípulos, e a marginalização de eros em prol de agape, que se especializa na referência a um amor próprio ao cristianismo. É uma "nova visão do amor que se exprime através da palavra agape”, uma "novidade do cristianismo, algo de essencial e próprio relativamente à compreensão do amor". Por isso a expressão da opção fundamental da vida cristã é: "Nós cremos no amor de Deus". Amor que, em latim, dir-se-á caritas.

Na breve definição papal, esse é "o amor que Deus oferece de modo misterioso e gratuito ao homem, juntamente

\footnotetext{
${ }^{3}$ A partir daqui, todas as citações de Bento XVI, salvo quando houver indicação em contrário, provêm deste texto.

${ }^{4} \mathrm{O}$ Dicionário grego-português dá os seguintes significados para agape. "amor, predileção, afeição, amor divino, fraternidade, caridade" (Malhadas, Dezotti e Neves, 2006).
} 
com o nexo intrínseco daquele Amor com a realidade do amor humano". Portanto, um amor que se desdobra em duas dimensões. Primeiramente, amor de Deus pelo homem e amor do homem por Deus; é o amor que o homem recebe de Deus e pelo qual responde a Deus; logo, aquele pelo qual se dá a "unificação do homem com Deus". Depois, é o amor do homem por seu próximo; aquele que, recebido de Deus, "deve ser comunicado aos outros por nós".

A unidade dessas dimensões de um mesmo amor (Deushomem-Deus, homem-homem) revela, diz Bento XVI, a alma do cristianismo: "Amor a Deus e amor ao próximo são inseparáveis, constituem um único mandamento.” É pela síntese das duas dimensões que Cristo pode, ao mesmo tempo. acolher o "núcleo da fé de Israel" e dar-lhe "uma nova profundidade e amplitude". O Deus de Israel "ama pessoalmente", e nessa medida é superior ao Deus da filosofia; a inovação verdadeiramente cristã que aprofunda tudo isso, porém, é igualar o 202 amor a Deus ao amor ao próximo, juntando o que no Antigo Testamento surge em separado no Deuteronômio ("Amarás ao Senhor, teu Deus") e no Levítico ("Amarás o teu próximo como a ti mesmo") ${ }^{5}$. É por aí que se chega a uma capital redefinição da noção de "próximo", que não mais se referirá só ao membro de uma comunidade, como no judaísmo. "Agora”, explica o papa, "este limite é abolido. Qualquer um que necessite de mim e eu possa ajudá-lo, é o meu próximo”.

Digamos então com São Paulo: "uma vez que há um só pão, nós, embora sendo muitos, formamos um só corpo, por-

\footnotetext{
5 "O crente israelita, de fato, reza todos os dias com as palavras do Livro do Deuteronômio, nas quais sabe que está contido o centro da sua existência: 'Escuta, ó Israel! O Senhor, nosso Deus, é o único Senhor!, com todo o teu coração, com toda a tua alma e com todas as tuas forças' $(6,4-5)$. Jesus uniu - fazendo deles um único preceito - o mandamento do amor a Deus com o do amor ao próximo, contido no Livro do Levítico: 'Amarás o teu próximo como a ti mesmo' (19, 18; cf. Mc 12, 29-31). Dado que Deus foi o primeiro a amar-nos (cf. 1 Jo 4, 10), agora o amor já não é apenas um 'mandamento', mas é a resposta ao dom do amor com que Deus vem ao nosso encontro."
} 
que todos participamos do mesmo pão”. Com a redenção de Cristo todos os homens passam a ser iguais perante Deus; a imagem e semelhança da criatura com relação ao criador estabelece uma identidade superior, uma universalidade nunca antes auspiciada por nenhuma religião: esta identidade é a do amor. E isso nos encaminha para uma metafísica do amor, quase uma ontologia em que o ser se diz amorosamente. Deus é uma razão primordial, mas também um amante, uma espécie de lógos amante que funda uma realidade cujos vários planos unificam-se pela subsunção a um mesmo amor ${ }^{6}$.

Ora, a partir dessas teses, e pensando na questão que propusemos, a tolerância, cabe perguntar: como fica o diferente? A resposta exige precisar uma conseqüência nada desprezível desse esquema: sendo a identidade superior o amor, sem ele, sem esse amor essencial, o homem é incompleto; o amor dá ao homem a completude, sem tal amor há a falta, o homem sente carecer de algo. A imagem apropriada, aqui, é o Adão que necessita de outrem, carne de sua carne: Eva. É aí, nessa incompletude do homem que corre ao largo da identidade fornecida por agape/caritas, que a doutrina de Bento XVI demonstra-se ferrenha inimiga da idéia de tolerância. Não sem alguma sutileza, ela promove uma ênfase excessiva da igualdade/identidade e, por conseqüência, um desequilíbrio na lógica da tolerância que acarreta, se não a supressão, ao menos o desprivilégio da diferença.

Para chegarmos a esse ponto, caberá salientar um movimento onipresente nos textos de Bento XVI e que responde pela unificação de todas as dimensões do ser sob o signo da verdade superior constituída pelo amor: a idéia de purificação. É por esta que se tornam compreensíveis os vários

\footnotetext{
${ }_{6}$ "O aspecto filosófico e histórico-religioso saliente nesta visão da Bíblia é o fato de, por um lado, nos encontrarmos diante de uma imagem estritamente metafísica de Deus: Deus é absolutamente a fonte originária de todo o ser; mas este princípio criador de todas as coisas - o Logos, a razão primordial - é, ao mesmo tempo, um amante com toda a paixão de um verdadeiro amor."
} 
pares de termos opostos que encontramos nos documentos papais: eros $\times$ agape, degradação do homem $\times$ elevação do homem, iluminismo $\times$ iluminismo autêntico, monoteísmo $\times$ politeísmo, monogamia $\times$ poligamia etc. A passagem de um pólo a outro é sempre pensada à maneira de uma purificação. Como exemplo, tomemos a oposição entre eros e agape, desenvolvida na resposta do papa à acusação nietzschiana de que o cristianismo teria envenenado eros dando forma a uma vida amarga. Nada disso, dirá Bento XVI, “o eros necessita de disciplina, de purificação" para juntar-se a agape e assumir sua plenitude, dando "ao homem, não o prazer de um instante, mas uma certa amostra do vértice da existência, daquela beatitude para que tende todo o nosso ser"; "são necessárias purificações e amadurecimentos que passam também pela estrada da renúncia”. Só que isso não é a renúncia a eros, e sim sua purificação em agape: "O eros é enobrecido ao máximo, mas simultaneamente tão purifica204 do que se funde com a agape". É só assim que "se insere nele o momento da agape; caso contrário, o eros decai e perde mesmo a sua própria natureza.”

É o mesmo movimento que encontramos ao pensar a possibilidade do amor ao próximo naquele sentido amplo trazido pelo cristianismo, e especialmente ao próximo "que não agrada e que desconheço". Vejamo-lo:

1ㅇ) Posso amar o próximo, mas peculiarmente este amor se dá em Deus. Como Malebranche via em Deus, Bento XVI ama em Deus.
"Revela-se, assim, como possível o amor ao próximo no sentido enunciado por Jesus [...] eu amo, em Deus e com Deus, a pessoa que não me agrada ou que nem conheço sequer"7.

\footnotetext{
${ }^{7}$ A passagem fundamental aqui em consideração é a seguinte: "Revela-se, assim, como possível o amor ao próximo no sentido enunciado por Jesus, na Bíblia. Consiste precisamente no fato de que eu amo, em Deus e com Deus, a pessoa que não
} 
$2^{\circ}$ ) Se amo em Deus, amo o outro sempre pela perspectiva da verdade superior. "Eu vejo com os olhos de Cristo", afirma o papa. A efetivação do amor em geral, e em particular do amor por aquele que me desagrada e que desconheço, exige uma mediação que é também uma purificação do outro. Ou seja, o próximo diferente, pela mediação da verdade, é purificado e pode tornar-se objeto de amor porque feito idêntico, perfeitamente subsumível à verdade unificadora do Deus católico; ele é subsumido ao termo "próximo" pelo despojamento de todos os seus elementos diferenciais.

Ora, qual o pressuposto da efetivação desse amor? Justamente a incompletude do homem que não se integra ao amor cristão, a incompletude e a mácula do diferente que não se subsume ao idêntico; como se disse há pouco de eros: sem agape, ele "decai e perde mesmo a sua própria natureza". O homem, ao largo da identidade, resta lacunar, incompleto e, uma vez que sequer chega a ser um "próximo", não pode ser amado; no limite, "perde sua própria natureza”, faz-se sub-humano. E sublinhemos esta última idéia, a ler-se sob a fórmula "verdadeira humanização", utilizada no discurso de abertura da CELAM (Bento XVI, 2007) ${ }^{8}$, e que pensamos dever ser entendida quase como referência a um processo de hominização. Purificar-se, tornar-se "próximo" pela subsunção ao amor, é a única via de fazer-se homem, safar-se da incompletude e sub-humanidade.

Sob esse aspecto, o amor apregoado por Bento XVI toma a forma de um poderoso instrumento de desqualifi-

me agrada ou que nem conheço sequer. Isto só é possível realizar-se a partir do encontro íntimo com Deus, um encontro que se tornou comunhão de vontade, chegando mesmo a tocar o sentimento. Então aprendo a ver aquela pessoa já não somente com os meus olhos e sentimentos, mas segundo a perspectiva de Jesus Cristo. O seu amigo é meu amigo. Para além do aspecto exterior do outro, dou-me conta da sua expectativa interior de um gesto de amor, de atenção, que eu não lhe faço chegar somente através das organizações que disso se ocupam, aceitando-o talvez por necessidade política. Eu vejo com os olhos de Cristo”.

${ }^{8} \mathrm{O}$ trecho em questão está citado na próxima nota. Lembremos também que outro texto fala de uma "verdadeira humanidade, que nasce do sermos tocados por Jesus Cristo” (Bento XVI, 2006b). 
cação do diferente e a redução deste a um estado lacunar. Uma vez afirmada a identidade superior, os outros podem até manter sua diferença, mas sempre serão incompletos, defeituosos, faltar-lhes-á algo e vão se situar como que fora do horizonte do ser: a diferença e o diferente são pura aberração, quase não-ser, já que, situado no universo de um ser amoroso, é impossível objeto de amor. Não nos admiremos, pois, com os pontos de vista daí decorrentes, que não deixam de exibir grande coerência doutrinária. O muçulmano é uma espécie de bárbaro violento se não adota a fé cristã; o protestante não é um legítimo cristão se não se integra e se submete à única igreja de Cristo; a razão pode até conseguir algo sozinha, mas não terá acabamento sem a fé; o indígena americano não seria feliz caso os conquistadores europeus não tivessem trazido para cá o cristianismo, possibilitando a "humanização" dos índios, a atualização de uma humanidade que eles procuravam inconscientemen206 te assim como procuravam Cristo: buscavam Jesus para tornarem-se humanos, e é tal encontro, a evangelização, que os purifica e humaniza/hominiza. Neste ponto, vale a pena prestar atenção à argumentação de Bento XVI, um exemplo acabado de seu modo de raciocinar. Para os indígenas, ele afirma, a evangelização não constituiu alienação nem imposição porque:

"significou conhecer e acolher Cristo, o Deus desconhecido que os seus antepassados, sem o saber, buscavam nas suas ricas tradições religiosas. Cristo era o Salvador que esperavam silenciosamente. Significou também ter recebido, com as águas do batismo, a vida divina que fez deles filhos de Deus por adoção; ter recebido, outrossim, o Espírito Santo que veio fecundar as suas culturas, purificando-as e desenvolvendo os numerosos germes e sementes que o Verbo encarnado tinha lançado nelas, orientando-as assim pelos caminhos do Evangelho" (Bento XVI, 2007 - itálicos nossos). 
É isso, e só isso, que ao fim e ao cabo outorga aos selvagens o "progresso autêntico" de uma "verdadeira humaniza-

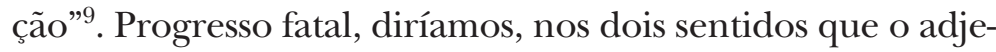
tivo admite: inevitável, pois determinado por uma identidade escondida que só espera a ação do conquistador para pôr-se em movimento; mortal, pois literalmente é preciso matar o selvagem para deixar nascer o homem, o meu "próximo"10.

As lutas religiosas, por seus efeitos violentos, nunca deixaram de preocupar aqueles que se dedicaram a pensar a política e a vida social. Não seria a intolerância, quer da parte das leis, quer da população, um veneno a corroer a possibilidade uma vida segura e livre? Sim, e por isso o alvorecer do Estado moderno é inseparável de uma reflexão sobre a tolerância e já no século XVII encontramos dois produtos maiores desse processo no Tratado teológico-político (1670), de Espinosa, e na Epistola sobre a tolerância (1689), de Locke; textos que se esforçam por demonstrar que a tolerância é

\footnotetext{
${ }^{9}$ Ver a seqüência do texto que acabamos de citar: "Em última instância, somente a verdade unifica, e a sua prova é o amor. Por isso Cristo, dado que é realmente o Logos encarnado, "o amor até ao extremo", não é alheio a qualquer cultura, nem a qualquer pessoa; pelo contrário, a resposta desejada no coração das culturas é o que lhes dá a sua identidade última, unindo a humanidade e respeitando, ao mesmo tempo, a riqueza das diversidades, abrindo todos ao crescimento na verdadeira humanização, no progresso autêntico" (Bento XVI, 2007; itálicos nossos) Um argumento que, curiosamente, faz ressoar a Crítica da razão pura, quando Kant sugere que o esclarecimento do entendimento nos conduz naturalmente ao monoteísmo, sempre procurado por todos os povos, ainda que não o saibam: "eis porque em todos os povos, no meio do mais cego politeísmo, reluzem algumas centelhas de monoteísmo a que foram levados, não por reflexão nem profundas especulações, mas somente pela marcha natural do entendimento comum, que gradualmente se vai esclarecendo" (Kant, 1985, 499, B 618) Vê-se, por tal paralelo, como a doutrina papal embasa-se na história da filosofia e o que pode ser o "iluminismo autêntico" que ela opõe a um iluminismo condenável.

${ }^{10}$ Por incertos e controversos que possam ser as cifras em jogo, é difícil negar que a "evangelização" da América se tenha dado à base da destruição cultural e do genocídio: para ficar num só exemplo, a população do planalto mexicano, estimada em 25 milhões à época do descobrimento, vê-se reduzida a 1,9 milhões oitenta anos depois (cf. Bethell, 2004).
} 
não só uma liberalidade que o governante pode conceder ou não, mas elemento indispensável à própria estabilidade social. São idéias de longo curso e que entrarão de vez na esfera pública à época do Iluminismo, quando a tolerância religiosa surgir ao lado de outra idéia então saliente: a afirmação de que "todos os homens são iguais por natureza", tal como ganha forma na Declaração dos Direitos do Homem e do Cidadão (1793).

Bento XVI (cujos textos não escondem a má vontade com o Iluminismo) deve aprovar esta última idéia, mas noutros termos: todos são iguais porque todos são igualmente criaturas de Deus (o católico, naturalmente). É algo bem diverso. Se com o Iluminismo a afirmação da igualdade reforçava a tolerância, com o papa ela leva à condenação do diferente, portanto, à intolerância. $\mathrm{O}$ raciocínio pode ser o seguinte: somos todos iguais por obra do criador, logo devemos todos ser ovelhas do criador e comungar de uma mesma 208 identidade superior (o amor) que nos foi por ele conferida; os que se recusam a isso, só podem ser rebeldes e pecadores, uma espécie de sub-humanos, já que desajustados à única humanidade possível, em Cristo e em sua Igreja.

A conclusão é perversa: quem não é igual e está na verdade, é diferente e está na mentira; quem não aceita a condição de criatura de Deus, vê-se despojado de sua própria humanidade. Conseqüência extrema dessa lógica: o diferente é passível de todas as atrocidades reservadas aos inumanos.

Ora, quando nos primeiros anos da colonização da América espanhóis alimentavam seus cães com crianças indígenas ou se divertiam a caçar os adultos ${ }^{11}$, talvez não os movesse uma crueldade desmedida, somente uma monstruosa incapacidade de ver ali, naqueles pequenos não batizados e naqueles homens e mulheres idólatras, outros seres humanos. Esse

\footnotetext{
${ }^{11}$ Veja-se toda a Brevíssima relação da destruição das Índias de Bartolomé de Las Casas. Para os casos aqui mencionados, especialmente Las Casas, (2007, pp. 75 e 121).
} 
anátema maior do não ser como eu ou nós, tudo podia justificar, inclusive a negação da humanidade dos índios. Incapacidade assustadora e brutal, sem dúvida, mas que não pertence só ao passado. É a mesma que se revela quando, "para zoar", jovens espancam prostitutas ou matam homossexuais; a diferença da prostituição ou da homossexualidade é que macula as vítimas a ponto de subtrair-lhes a humanidade e reduzi-las a peças de um divertimento macabro.

Guardadas as proporções, é a mesma incapacidade que o papa revela em seu ainda curto pontificado. O muçulmano, o protestante, os índios, serão todos sub-humanos até se integrarem à identidade superior sob a guarda da Igreja Católica. Como o pontífice afirmou na abertura da V Conferência do episcopado latino-americano: "em última instância, somente a verdade unifica” (Bento XVI, 2007). De fato, e enquanto não for assim tudo se poderá, em nome da verdade absoluta instalada no além, contra os que grassam na mentira em nosso aquém.

O problema de Bento XVI não é ser católico - ninguém espera outra coisa de um papa -, mas o atentado contra a tolerância religiosa e o respeito às diferenças que sua nova ortodoxia vem promovendo. Para que eu ame o próximo como a mim mesmo, o próximo deve começar sendo igualzinho a mim mesmo. A esse novo catolicismo, é impossível amar o outro, respeitá-lo como um ser humano pleno em sua diferença, como um ser singular. $\mathrm{O}$ amor, em verdade, torna-se aqui, primeiro, um achincalhe do outro que é diferente, para logo depois tomar a forma de um desejo de destruição desse outro. Daí, por fim, tornar-se um terrorismo no plano das idéias que não faz senão sucumbir a possibilidade de uma harmonia respeitosa entre os homens, semeando o fundamentalismo, a intolerância e a violência.

\section{Homero Santiago}

é professor do Departamento de Filosofia da FFLCH-USP 


\section{Referências bibliográficas}

AMARY, M. L. 2007. "Uma boa influência”. Folha de S.Paulo, São Paulo, 29 set.

BENTO XVI. 2005. "Carta encíclica Deus caritas est do Sumo Pontífice Bento XVI aos presbíteros e aos diáconos, às pessoas consagradas e a todos os fiéis leigos sobre o amor cristão”. Disponível em: http://www. vatican.va/holy_father/benedict_xvi/encyclicals/documents/hf_benxvi_enc_20051225_deus-caritas-est_po.html.

. 2006a. "Fé, razão e universidade: recordações e reflexões.

Aula Magna na Universidade de Regensburg”. Disponível em: http:/ / www.vatican.va/holy_father/benedict_xvi/speeches/2006/september/documents/hf_ben-xvi_spe_20060912_university-regensburg_ po.html.

2006b. "Homília do Santo Padre na solene concelebração eucarística no Islinger Feld, Regensburg”. Disponível em: http:/ /www. vatican.va/holy_father/benedict_xvi/homilies/2006/documents/hf_ ben-xvi_hom_20060912_regensburg_po.html.

2007. "Discurso na sessão inaugural dos trabalhos da V Conferência Geral do Episcopado da América Latina e do Caribe”. Disponível em: http://www.vatican.va/holy_father/benedict_xvi/speeches/2007/may/documents/hf_ben-xvi_spe_20070513_conferenceaparecida_po.html

BETHELL, L. 2004. "Nota sobre as populações americanas às vésperas das invasões européias”. In: (org.). História da América Latina, vol. I: América Latina Colonial. Tradução de Maria Clara Cescato. São Paulo: Edusp.

CARDOSO, S. 2004. Retorno ao republicanismo. Belo Horizonte: Ed. UFMG.

CHAUI, M. 2004. "O retorno do teológico-político". In: CARDOSO, S. Retorno ao republicanismo. Belo Horizonte: Ed. UFMG.

KANT, E. 1985. Crítica da razão pura. Tradução de Manuela Pinto dos Santos e Alexandre Fradique Morujão. Lisboa: Fundação Calouste Gulbenkian.

LAS CASAS, B. de. 2007. O paraíso perdido. Tradução de Heraldo Barbuy. Porto Alegre: L\&PM.

MALHADAS, D.; DEZOTTI, M. C. C.; NEVES, M. H. de M. (coords.). 2006. Dicionário grego-português. Cotia, SP: Ateliê Editorial.

PONDÉ, L. F. 2002. "O descompasso da razão: entrevista com Alain de Libera”. IHU on-line (revista do Instituto Humanitas Unisisinos), São Leopoldo-RS, $\mathrm{n}^{\circ}$ 38, 7 set. Disponível em: http://www.unisinos.br/ ihuonline/uploads/edicoes/1161370937.58pdf. 


\section{OS EXCESSOS DA IDENTIDADE: BENTO XVI E A QUESTÃO DA TOLERÂNCIA}

HOMERO SANTIAGO

Partindo de algumas das polêmicas opiniões de Bento XVI, o artigo busca compreender a base doutrinária delas e discutir os seus efeitos para a questão da tolerância religiosa. Depois de uma apresentação do que entende por tolerância, propõe um percurso através da encíclica Deus caritas est, que embasa a nova doutrina papal numa interpretação particular da noção de "amor de Deus". Por fim, tenta-se mostrar como esse "amor", mediante uma ênfase exagerada da idéia de identidade, torna-se nos documentos papais um instrumento de combate a todas as diferenças, pondo a perder a possibilidade de convivência entre as religiões e, por conseqüência, semeando o fundamentalismo.

Palavras-chave: Bento XVI; Cristianismo; Tolerância religiosa; Diferença; Religiões.

\section{EXCESSES OF IDENTITY: BENEDICT XVI AND THE ISSUE OF TOLERANCE}

This article tries to comprehend the doctrinal base of some polemical assessments of Benedict XVI; discussing its effects on the issue of 
religious tolerance. After presenting what is understood to mean tolerance, it proposes a way through the encyclical letter Deus caritas est; in this letter, the new papal doctrine is founded on a particular interpretation of the notion of "God's love". Lastly, it intends to show how this "love", by an exaggerated emphasis on the idea of identity, becomes an instrument of fight against every difference, spoiling the possibility of a pacific relationship among the religions and, consequently, sowing the seeds of fundamentalism.

Keywords: Benedict XVI; Christianity; Religious Tolerance; Difference; Religions. 